\title{
Aplicação da técnica de imunoensaio enzimático de multiplicação (EMIT) para dosagem de ciclosporina na amostra de sangue absorvido em papel-filtro
}

\author{
Application of the enzyme-multiplied imunoassay technique (EMIT) to measure ciclosporin in the blood sample \\ absorbed in filter paper
}

Hui Tzu Lin-Wang'

Ricardo Manrique ${ }^{2}$

\begin{abstract}
unitermos resumo
Ciclosporina

Técnicas imunoenzimáticas

Objetivo: Investigar a aplicabilidade da técnica de imunoensaio enzimático de multiplicação

(enzyme-multiplied immunoassay technique - EMIT) para dosagem de ciclosporina A (CsA) nas

amostras de sangue absorvido em papel-filtro (STAP). Material e método: Realizaram-se

EMIT

determinações de CSA utilizando-se técnica de EMIT em 110 amostras; 24 eram de pacientes

Papel-filtro

transplantados cardíacos e 86, dos pacientes transplantados renais. Todos faziam uso da CsA

Monitorização de

por via oral. Exatamente 12 horas após a tomada da CsA, coletou-se o sangue e prepararam-

medicamento

se as amostras de STAP. As amostras de STAP foram estocadas à temperatura ambiente por

períodos de 15 e 30 dias, e as amostras de sangue total foram estocados a $\pm 4^{\circ} \mathrm{C}$, por um

Transplante

tempo inferior a 48 horas, para o teste. Resultados: O coeficiente de correlação entre a

técnica que utiliza como amostra sangue total e a amostra de STAP realizada 15 dias após a

preparação foi de 0,963, e de 30 dias foi de $0,972(p<0,0001)$. A correlação entre as

amostras de STAP de 15 e 30 dias foi de 0,968 ( $p<0,0001)$. A análise de variância não-

paramétrica de Friedman para os três grupos comparados revelou que ela não foi estatistica-

mente significante $(p>0,005)$. Conclusões: A técnica de STAP pode ser utilizada rotineira-

mente por ser estável, reprodutível e prática. Considerando-se a dimensão continental de

muitos países, este método pode ser bastante útil para a otimização da terapia.
\end{abstract}

\section{abstract}

Objective: The purpose of this work is to research the applicability of the Enzyme-multiplied imunoassay technique (EMIT) to measure Ciclosporin A (CSA) in the whole blood sample absorbed in filter paper (STAP). Methods: It was performed dosage of CSA in 110 blood samples: 24 samples in patients with heart transplantation and 86 patients of renal transplantation. All of them were using CSA orally. Just 12 hours after the last CSA intake, the blood was collected and the STAP samples were prepared. The STAP samples were stored at room temperature for a period of 15 and 30 days. The whole blood samples were stored at about $4^{\circ} \mathrm{C}$ for a time lower than 48 hours to the test. Results: The coefficient of correlation between the whole blood and the STAP samples of 15 days was 0.963 and 30 days was $0.972(p<0.0001)$. The coefficient correlation between the STAP samples measured after 15 and 30 days was $0.968(p<0.0001)$. The Friedman non-parametrical variance analysis for the three groups compared revealed it was not statistically significant $(p>0.005)$. Conclusions: The STAP technique can be used in the clinic practice, because it is stable, reproducible and practical. Considering the wide continental dimension of many countries, such method can be quite useful to optimize the therapy. 


\section{Introdução}

A ciclosporina é uma droga imunossupressora isolada originalmente do fungo Tolypocladium inflatum gams. Devido às diferenças estruturais dos peptídeos que formam as suas moléculas, ela é classificada em ciclosporinas A, C, D e G (11). A ciclosporina A (CsA) foi introduzida em 1978, para o tratamento dos transplantes alogênicos (4). Ela possui como vantagem a baixa nefrotoxicidade e, ao contrário dos corticosteróides e das azatriopinas, nas concentrações terapêuticas adequadas não causa mielossupressão $(4,11)$.

A janela terapêutica da CsA é muito estreita, doses reduzidas carecem de efeito imunossupressor e doses excessivas induzem a reações adversas, tais como: nefrotoxicidade, hepatotoxicidade, distúrbios gastrintestinais, tremores, hiperplasia gengival, tricose, lesão renal irreversível, fibrose cardíaca e hipertensão arterial severa $(4,11)$. Por esta razão a monitorização periódica é essencial para a otimização da terapia.

Existem atualmente no mercado várias técnicas disponíveis para dosagem de CsA sangüínea. A cromatografia líquida de alto desempenho (high performance liquid chromatographic - HPLC), a primeira técnica utilizada, fornece resultados bastante precisos e específicos, porém é de difícil automatização, com custo elevado e procedimentos trabalhosos $(2,9)$.

A técnica de radioimunoensaio (radioimmunoassay - RIA) foi descrita pela primeira vez em 1981 para determinação de CsA sangüínea (4). Na época, representou um avanço importante, porém exigia equipamento específico e pessoal técnico especializado para manuseio do material radioativo.

Em 1990, foi desenvolvido um imunoensaio monoclonal específico para a CsA, utilizando fluoresceína como marcador (fluorescence polarization immunoassay - FPIA). É um método alternativo ao RIA, com as vantagens de ser rápido, de fácil execução e reprodutível, sem apresentar as desvantagens do RIA com relação a tempo de validade dos reagentes, manipulação e descarte de material radiativo (3).

A técnica de imunoensaio enzimático de multiplicação (enzyme-multiplied immunoassay technique - EMIT) foi considerada a melhor técnica da atualidade para dosagem de $\operatorname{CsA}(2,6,9,10)$, porque confrontaram-se os resultados obtidos por meio das técnicas de RIA, FPIA e EMIT com os de HPLC, esta última considerada o padrão -ouro. A EMIT apresentou maiores sensibilidade e espe- cificidade, sendo mais econômica que outras técnicas, porque a curva padrão é estável por mais ou menos um mês, e isto representa uma economia significativa de quase $30 \%$ do custo do reagente (10), além de permitir a realização do teste a qualquer momento, sem a necessidade de uma nova calibração, o que não seria possível no RIA devido ao decaimento da atividade do radioisótopo utilizado no teste.

O uso de CsA necessita de determinações periódicas dos níveis sangüíneos para monitorizar a dose terapêutica, com a finalidade de obter o efeito imunossupressor ideal, reduzindo os riscos de rejeição devidos a subdose do medicamento, ou toxicidade causada pelo excesso de medicamento no organismo. Esta conduta cuidadosa com o nível de CsA sangüíneo favorece a vida útil do enxerto, também proporcionando melhor qualidade de vida ao paciente. Os custos com os pacientes também diminuem, pois, quando livres de complicações adversas, não precisarão de tratamentos complementares nem de internações hospitalares prolongadas.

Oferecer o maior controle de CsA sangüínea aos pacientes clinicamente estáveis, que residem longe dos centros transplantadores, sempre foi um desafio para a equipe de transplante, pois, onde moram estes pacientes, na maioria das vezes não há laboratórios equipados nem pessoal técnico treinado. Comparecer com freqüência ao hospital, para fazer exames de rotina, é um trabalho árduo para os pacientes, pois para isto dependem da situação econômica, e, muitas vezes, depois do transplante, eles conseguem a recolocação no mercado de trabalho, não podendo faltar ao serviço por longos períodos.

Com o propósito de solucionar este problema, idealizamos a técnica para dosagem de CSA nas amostras de sangue total absorvido em papel-filtro (STAP), aplicando a técnica de RIA, que utilizava o antígeno marcado com trício (8) e iodo-125 (7). Posteriormente, a eficiência da técnica também foi confirmada por Azevedo et al. (1). Diante das vantagens que a técnica de EMIT apresenta, tornou-se importante adaptá-la para ser utilizada nas amostras de STAP.

\section{Objetivo}

Investigar a aplicabilidade da técnica de EMIT para as amostras de sangue absorvido em papel-filtro (STAP) e a sua reprodutibilidade após 15 e 30 dias, mediante estudo comparativo com as amostras de sangue total (ST). 


\section{Material e método}

\section{Amostras}

Foram obtidas 110 amostras na rotina do Laboratório de Pesquisas Especiais do Instituto Dante Pazzanese de Cardiologia, no período de 8/5/2000 a 11/9/2000, das quais 24 eram de pacientes transplantados cardíacos e 86, de pacientes transplantados renais.

\section{Procedimentos}

Foi realizado previamente um estudo piloto com 20 amostras, e, com base nos dados obtidos, foi calculado o tamanho mínimo da amostra. Considerou-se uma precisão absoluta de 10\% e nível de significância de 5\%, aceitando-se uma variação entre dois métodos comparados de $20 \mathrm{ng} / \mathrm{ml}$. O número estimado para cada grupo foi de 94 amostras.

O estudo foi realizado em um protocolo cego, no qual cada amostra era identificada com códigos diferentes para cada método realizado. O examinador era a mesma pessoa, porém sem informações de identificação das amostras. Os dados foram cruzados somente ao final da pesquisa.

Todos os pacientes usavam, por via oral, ciclosporina em microemulsão (Sandimun Neoral ${ }^{\circledR}$ ou Sigmasporin ${ }^{\circledR}$ ) como parte da terapia de imunossupressão. Na coleta do sangue utilizaram-se tubos contendo o anticoagulante ácido etilenodiaminotetracético (EDTA), e ela foi realizada exatamente 12 horas após a última dose da medicação, com o paciente em jejum (11).

No mesmo dia da coleta do espécime, realizou-se o preparo da amostra de STAP. O papel-filtro utilizado foi da marca Nalgon ${ }^{\circledR}$, papel para filtração qualitativa, peso de $80 \mathrm{~g} / \mathrm{m}^{2}, 9 \mathrm{~cm}$ de diâmetro, com porosidade de 3 micra e $0,5 \%$ de cinzas. 0 mesmo tubo de sangue foi estocado na geladeira a $4^{\circ} \mathrm{C}$ por um tempo inferior a 48 horas, para determinação de CSA na amostra de ST pelo método original da EMIT $(2,5,9)$. As dosagens de CsA das amostras de STAP foram realizadas 15 e 30 dias após a preparação.

\section{Preparação da amostra de sangue absorvido no papel-filtro}

1) Sobre um suporte de área central livre, que poderia ser um becker ou copo, colocou-se o papel, tendo-se o cuidado de deixá-lo bem esticado;

2) pipetaram-se e dispensaram-se sobre o papel $50 \mu l$ de sangue homogeneizado;
3) repetiu-se o processo anterior, fazendo-se seis aplicações de sangue em pontos distintos na superfície do papel;

4) deixou-se difundir e secar naturalmente, à temperatura ambiente;

5) guardou-se dentro de um saco plástico, à temperatura ambiente, por 15 e 30 dias, até o momento da realização do teste.

\section{Eluição das amostras}

Para a determinação de CsA nas amostras de STAP, foi necessário transformar as manchas sólidas em soluções aquosas, para se poderem realizar os ensaios bioquímicos. Para isto foram eluídas as amostras antes da reação.

1) Recortaram-se três manchas de STAP que correspondem a $150 \mu$ l de sangue total;

2) picotaram-se estas manchas de sangue em pedaços minúsculos, de mais ou menos $3 \mathrm{~mm}$, colocando-os num tubo de ensaio;

3) eluiu-se cada amostra com $0,9 \mathrm{ml}$ de tampão Tris (surfactante, azida sódica a 0,1\% e sulfato de estreptomicina a 0,005\%);

4) homogeneizou-se e aguardou-se por uma hora, deixando-se as amostras na temperatura ambiente (esta etapa pode ser interrompida e continuada depois de 24 horas);

5) passou-se para outro tubo de ensaio $0,6 \mathrm{ml}$ de sobrenadante, que corresponde a $0,1 \mathrm{ml}$ de sangue total;

6) secou-se o tubo com gás nitrogênio a uma pressão de 10 litros por minuto;

7) acrescentou-se $0,1 \mathrm{ml}$ de tampão Tris para ressuspender a amostra.

\section{Dosagem de CsA nas amostras de ST e STAP}

Para as determinações de CsA, tanto nas amostras de ST quanto nas de STAP, foi utilizado o reagente comercial EMIT-2000 ${ }^{\circledR}$ (Syva Co. Dade Behring Inc. CA) e feita análise no aparelho de bioquímica automatizada Cobas Mira (Roche Sistema de Diagnóstico, Montclair, NJ).

1) Extraiu-se a amostra $(0,2 \mathrm{ml}$ de ST ou $0,1 \mathrm{ml}$ de STAP) com $0,4 \mathrm{ml}$ de metanol;

2) agitou-se no Vortex;

3) centrifugou-se a 3.000rpm durante 10min;

4) pipetou-se $0,1 \mathrm{ml}$ de sobrenadante e passou-se para a cubeta; acrescentou-se 0,2ml de tampão Tris e homogeneizou-se; 
5) prosseguiu-se a dosagem no aparelho de bioquímica automatizada Cobas Mira, da marca Roche ${ }^{\circledR}$, e utilizou-se reagente EMIT-2000 ${ }^{\circledR}(2,5,9)$;

6) somente para as amostras de STAP, fez-se multiplicação por fator de diluição 2 para obter os resultados finais, lembrando que o volume utilizado na amostra de STAP é apenas metade do volume da amostra de ST.

\section{Análise estatística}

A análise estatística foi realizada com auxílio dos programas de análise estatística SPSS ${ }^{\circledR}$ (SPSS for Windows, Release 6.0, Chicago, SPSS Inc., 1993). Foi realizado o cálculo do coeficiente de correlação linear, confrontandose os três grupos estudados (sangue total, papel-filtro de 15 dias e papel-filtro de 30 dias). O nível de significância alfa adotado foi de $5 \%$. Utilizou-se também a análise de variância não-paramétrica de Friedman (12), porque as variáveis estudadas eram dos mesmos pacientes, e, portanto, as proporções não eram independentes.

\section{Resultados}

Os resultados das médias, desvios padrões e valores mínimos e máximos obtidos nas dosagens de CsA dos três grupos - ST, STAP de 15 e STAP de 30 dias - são observados na Tabela 1.

Realizou-se análise de variância não-paramétrica de Friedman (12); compararam-se simultaneamente os três grupos. O resultado encontrado não foi estatisticamente significante $(p=0,37)$ (Tabela 2).

O coeficiente de correlação entre as amostras de ST e as amostras de STAP realizadas 15 dias após a preparação foi de 0,963 , com $p<0,0001$ (Figura 1).

O coeficiente de correlação entre as amostras de ST e as de STAP realizadas 30 dias após a preparação foi de 0,972, com $p<0,0001$ (Figura 2).
O coeficiente de correlação entre as amostras de STAP de 15 e de 30 dias foi de 0,968, com $p<0,0001$ (Figura 3).

\section{Discussão}

O método de EMIT é uma técnica fácil e de rápida execução; a curva padrão é estável por mais ou menos um mês $(2,6,10)$. Além de contribuir para diminuir o custo do exame (10), permite realizar o teste a qualquer momento, sem necessidade de nova calibração. No caso

\begin{tabular}{lcl} 
& $\begin{array}{l}\text { Análise de variância não-paramétrica } \\
\text { de Friedman }\end{array}$ \\
\hline Variável & Média de postos & Resultado \\
ST $^{*}$ & 2,11 & Qui-quadrado $=2,005$ \\
STAP $^{* *} 15$ dias & 1,93 & Grau de liberdade $=2$ \\
STAP $^{* *} 30$ dias & 1,96 & $p=0,37$ \\
& & (não-significante)
\end{tabular}

*ST = sangue total; **STAP = sangue total absorvido no papel-filtro.

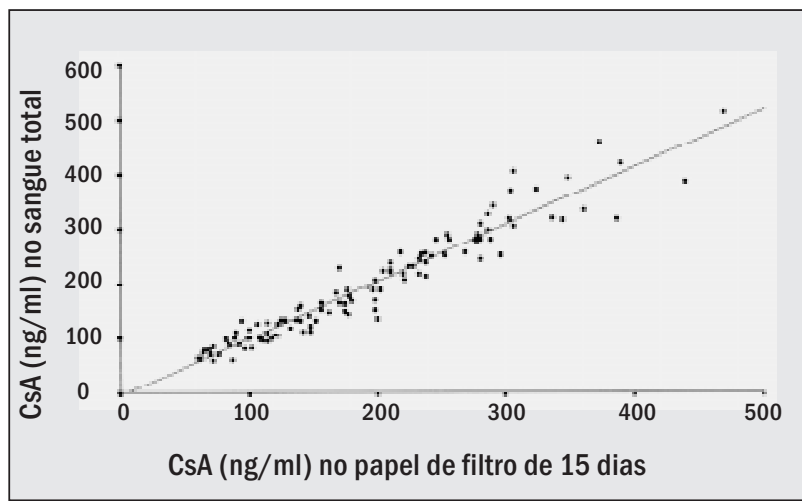

Figura 1 - Correlação linear entre as amostras de sangue total e amostras de papel de 15 dias $(r=0,963 ; p<0,0001)$

\section{Tabela 1 Média, desvio padrão e valores mínimo e máximo de cada grupo estudado}

\begin{tabular}{lccccc}
\hline Grupo estudado & $\begin{array}{c}\text { Número da } \\
\text { amostra }\end{array}$ & $\begin{array}{c}\text { Média } \\
(\mathrm{ng} / \mathrm{ml})\end{array}$ & $\begin{array}{c}\text { Desvio padrão } \\
(\mathrm{ng} / \mathrm{l})\end{array}$ & $\begin{array}{c}\text { Valor mínimo } \\
(\mathrm{ng} / \mathrm{ml})\end{array}$ & $\begin{array}{c}\text { Valor máximo } \\
\text { (ng/ml) }\end{array}$ \\
ST* $^{*}$ & 110 & 193 & 91 & 60 & 468 \\
STAP * $^{*}$ 15 dias & 110 & 197 & 96 & 65 & 432 \\
STAP** 30 dias & 110 & 197 & 99 & 61 & 514 \\
\hline
\end{tabular}

*ST = sangue total ; * *STAP = sangue total absorvido em papel-filtro. 


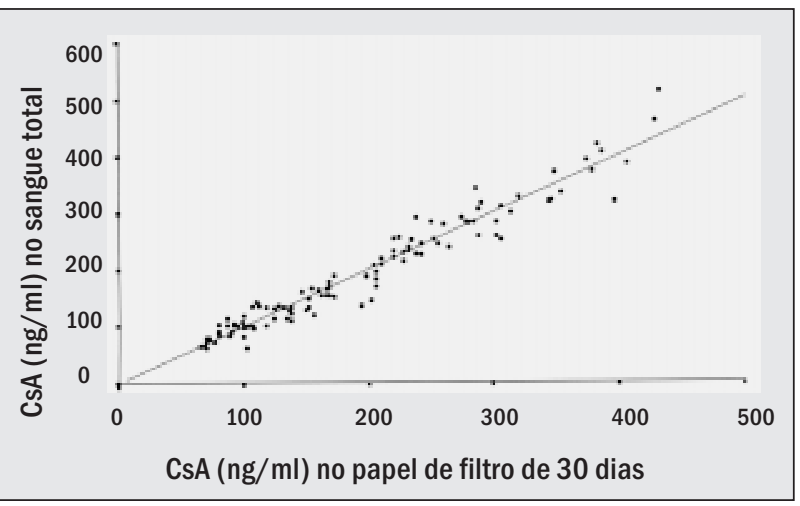

Figura 2 - Correlação linear entre as amostras de sangue total e amostras de papel de 30 dias $(r=0,972 ; p<0,0001)$

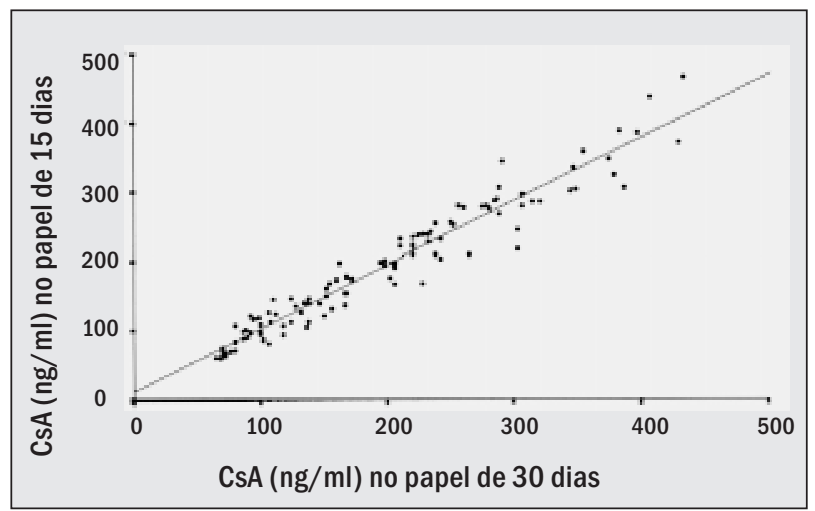

Figura 3 - Correlação linear entre as amostras de papel de 15 e 30 dias $(r=0,968$; $p<0,0001$ )

do RIA, isto não seria possível, devido ao decaimento da atividade do radioisótopo.

A nova técnica representará uma alternativa para os médicos e seus pacientes, e, além do custo menor do exame, devido à utilização intensiva dos reagentes e aproveitamento maior do equipamento e pessoal especializado, fará com que o paciente não precise se afastar do seu hábitat para ter acesso ao controle, pois as amostras de STAP podem ser transportadas sem refrigeração, como uma correspondência normal. Dessa forma, o médico pode solicitar maior número de testes para ajustar a dose de CsA a níveis terapêuticos seguros, evitando freqüência de internações por toxicidade ou rejeições e contribuindo, assim, para prolongar a vida útil do enxerto e melhorar a qualidade de vida do paciente.

A técnica alternativa de STAP proposta nesse trabalho merece algumas considerações.

Foi necessário concentrar amostras de STAP depois da eluição, pois, sem isso, a técnica recomendada pelo fabri- cante não apresentava sensibilidade suficientemente reprodutível.

Utilizamos gás nitrogênio para concentrar as amostras de STAP, porque ele é um gás não-inflamável e seca mais rapidamente as amostras por não conter oxigênio na sua molécula; porém pode apresentar um custo mais elevado. $\mathrm{O}$ ar comprimido também pode ser utilizado, mas demora quase o dobro de tempo para secar o mesmo volume de amostra.

A fase da extração de amostras com o metanol é de extrema importância para se obter resultados confiáveis e evitar falsas elevações. Recomendamos que a temperatura do ambiente de trabalho não ultrapasse $25^{\circ} \mathrm{C}$ e que o uso de centrífuga refrigerada para as amostras seja à temperatura constante de $4^{\circ} \mathrm{C}$, para evitar evaporação.

É necessário multiplicar os resultados obtidos das amostras de STAP pelo fator de diluição para se obter a concentração real de CsA sangüínea do paciente.

O procedimento de preparação da amostra de STAP é extremamente simples, podendo ser realizado em qualquer laboratório ou consultório médico (8). O método é de fácil automatização, permitindo ser executado rapidamente e com precisão $(2,5,6)$.

Considerando-se a dimensão continental de muitos países, este método pode ser bastante útil para a otimização da terapia.

\section{Conclusões}

Com base nos resultados obtidos neste trabalho, podemos concluir que:

- o método EMIT pode ser aplicado a amostras de STAP;

- há uma boa correlação entre amostras de ST e de STAP;

- as amostras de STAP são estáveis por pelo menos 30 dias;

- as dosagens de CsA utilizando técnica de EMIT para amostras de STAP fornecem resultados semelhantes aos de ST. Portanto, a técnica pode ser utilizada rotineiramente por ser estável, reprodutível e prática.

\section{Agradecimentos}

Ao professor-doutor Nagib Haddad, liderança científica do Instituto Dante Pazzanese de Cardiologia, pela revisão e análise estatística deste trabalho. 


\section{Referências}

I. Azevedo, L.S.; Manrique, R. \& Sabbaga, E. Comparação entre a dosagem de ciclosporina-A em amostras de sangue coletadas em papel de filtro e pela técnica habitual. Rev. Ass. Med. Brasil., 4 I (3): 183-6, 1995.

2. Beresini, M.H. et al. Evaluation of EMIT cyclosporine assay for use with whole blood. Clin. Chem., 39(II): 2235-4I, 1993.

3. Bottini, P.V. et al. Monitoramento dos níveis de ciclosporina em sangue total em transplantes renais. Rev. Ass. Med. Brasil., 44(3): 176-8, 1998.

4. Cohen, D.J. Cyclosporine: clinical applications and monitoring methods. Lab. Management., 23(I): 29-34, 1985.

5. Dasgupta, A.; Saldana, S. \& Desai, M. Analytical performance of EMIT cyclosporine assay evaluated. Clin. Chem., 37(12): $2130-3,1991$.

6. Legatt, D.F. et al. EMIT cyclosporine assay: development of an application protocol for Technicon AXON system. Clin. Biochem., 27(5): 387-94, 1994.
7. Lin-Wang, H.T. \& Manrique, R. Dosagem de ciclosporina em amostras transportadas de sangue absorvido em papel de filtro. Laes \& Haes, I / 8: 120-32, 1999.

8. Manrique, R.V. \& Lin, H.T. Optimization of the blood sample filter paper technique for cyclosporine determination. Transpl. Proc., 22(3): I231-3, 1990.

9. McBride, J.H. et al. Measurement of cyclosporine by liquid chromatography and three immunoassays in blood from liver, cardiac, and renal transplant recipients. Clin. Chem., 38( I I): 2300-6, 1992.

10. Sallustio, B.C. et al. Reducing the cost of cyclosporin assays: modification of the EMIT 2000 method. Drug. Monit., 19(2): 208-।I, 1997.

I I. Shaw, L.M. et al. Critical issues in cyclosporine monitoring: report of the task force on cyclosporine monitoring. Clin. Chem., 33(7): 1269-88, 1987.

12. Siegel, S. Estatística não paramétrica. São Paulo: McGraw-Hill Ltda., 1975. 